\title{
Assessment of earth surface pollution due to residual rocket fuel
}

\author{
Zhumagulov Bakhytzhan ${ }^{1}$, Abdibekov Ualikhan², Karzhaubayev Kairzhan ${ }^{2}$, Khikmetov Askar $^{2}$, \\ Zhubat Kuanysch ${ }^{3}$
}

${ }^{1}$ National Academy of Engineering of the Republic of Kazakhstan, Almaty, Kazakhstan

${ }^{2}$ Al-Farabi Kazakh National University, Faculty ofMechanics and Mathematics, Almaty, Kazakhstan

${ }^{3}$ Infrakos-Ekos, Geoinformation Department, Almaty, Kazakhstan

\section{Email address:}

bakhytzhan.zhumagulov@mail.ru(B. T.Zhumagulov), uali13@mail.ru(U. S. Abdibekov), kairzhan.k@gmail.com(K. K. Karzhaubayev), Askar.Khikmetov@kaznu.kz(A. K. Khikmetov),kivt@mail.ru(K.Zh. Zhubat)

\section{To cite this article:}

Zhumagulov Bakhytzhan, Abdibekov Ualikhan. Karzhaubayev Kairzhan,Khikmetov Askar, Zhubat Kuanysch. Assessment of Earth Surface Pollution due to Residual Rocket Fuel. Applied and Computational Mathematics. Vol. 2, No. 3, 2013, pp. 92-95.

doi: $10.11648 /$ j.acm.20130203.14

\begin{abstract}
This paper presents aerohydrodynamic modeling of air and surface pollution caused by toxic rocket fuel components. A numerical algorithm for solving this problem was developed and implemented in a software code in FORTRAN. Modeling of the dissimilation of rocket fuel dynamics for the case of the second-stage rocket "Proton-M" emergency fall was carried out using the developed software package. Finally, the modeling results were compared with a map of vegetation cover contamination in the region of the carrier-rocket second-stage fall.
\end{abstract}

Keywords: Aerohydrodynamic Modeling, Rocket Fuel Components, Heptyl, Environmental Investigation

\section{Introduction}

One of the environmental pollution sourcesin Kazakhstan arises from the dischargeof the first stages of untreatedrockets containing large amounts of residual propellant, including hundreds of kilogramsof highlyunsymmetricaldimethylhydrazine(UDMH).

Substancesin the first hazard class (Russia) and hazard class6.1 (U.S.), as potential carcinogens, are dangerousin any form of contact with living organisms. These substances damagethe centralnervous system and provoke seizures; they can also lead to disorders inthe gastrointestinaltract, respiratorytract and lungs and can result in organ tumors. It has been shown thatUDMHcan penetrate deeplyinto the soil anddissolvein surfacegroundwater; thus, the distribution of UDMH may spread over large areas.

Environmental pollution levels can be evaluated through mathematical modeling. This paper presents a methodology for forecasting the dissemination of rocket fuel components in regions of carrier-rocket part falls, considering the meteorological conditions.

Until recently, the influence of space rockets on ecology was not widely publicized, and the harmful effects of space activities on the environment have not been evaluated.
Analyses of the dissemination of toxic rocket fuel components have been generally considered in the works of Russian authors [1-3]; however, in the global scientific literature, there are no such methodological studies, due to the fact that foreigncarrier-rockets launches are conducted over ocean waters, where the above-mentioned separated rocket stages then fall.

\section{Materials and Methods}

To evaluate the level of environmental contamination caused by the spillage of residual propellant during the fall of the first stages of carrier rockets, the problem must be properly defined, i.e., the scenario and the main stages of the fuel spillage process must be determined and the initial and boundary conditions must be set. In this case, we consider only the process of surface contamination by heptyl, as the oxidizer is usually amyl or liquidoxygen, whicharelow-toxicityfuelcomponentswith lowevaporation temperaturesthat quickly transform intothe gaseous state and then rapidly mix with the ambient airat harmless concentrations.

The first detachment stage usually occurs at a height of nearly $4 \mathrm{~km}$. Only several hundred kilos of the UDMH 
remain in the tank at that point; for MBR SS20-type rockets, 273 kilos remain. After the first stage of detachment, three main scenarios are possible:

1) The fuel tanks are hermetically sealed, and fuel spillage occurs:

a) Into the troposphere upon tank breakage due to excessive heating pressure from atmospheric air friction;

b) On the ground surface, when the fuel tanks explode by hitting the earth's surface;

2) The fuel tanks become unsealed immediately after the detachment stage; due to their inertia, the tanks will rise up for some time and then an outflow of heptyl will occur at altitudes of $30-45 \mathrm{~km}$.

Variant 1a) - fuel spillage in the troposphere. This case has already been studied by our group in previous work [4]. Numerical computer models were developed and validated for this case. To detect the area of contamination for this variant, the exact coordinates of the fuel tanks' explosion and the meteorological fields at the instant of explosion must be known.

Variant 1b) - fuel spillage as a result of ground impact. In such cases, spontaneous self-ignition may occur, and the quantity of the remaining fuel, which will spread to the adjacent territories under the influence of air flows, is the main parameter to define. If the coordinates of the fuel tanks' fall and the quantity of remaining fuel are known, as well as the local meteorological conditions at the time of the fall, the dispersion of this cloud and the toxic fallout fields can be calculated with the help of hydrodynamic modeling.

Variant 2) - fuel spillage in the stratosphere. The heptyl transforms into aerosol in the form of liquid or frozen droplets. Considering the physical and chemical characteristics of heptyl and the conditions in the atmospheric layer [5], the maximum droplet size will not exceed $3 \mathrm{~mm}$ in radius. After falling from a height of $60 \mathrm{~km}$, most of the aerosol droplets will vaporize in the stratosphere, while the largest ones will evaporate completely in the troposphere. Thus, all of the spilled heptyl will vaporize and mix with air to low concentrations that cannot be detected by existing methods.

In this paper, different versions of variant $1 \mathrm{~b}$ ) were calculated and modeled because the most complete information is available for this case.

Using a surface atmosphere mesometeorological model, we have built a mathematical model of the aerosol admixture transfer of rocket fuel components in the surface layer [6-8], which includes the continuity equations, equations of motion and state equations. We have also developed a numerical scheme and a corresponding algorithm $[9,10]$.

The mathematical model of the atmosphere for mesoscale processes is of the following form:

$$
\begin{gathered}
\frac{\partial u_{1}}{\partial t}+u_{j} \frac{\partial u_{1}}{\partial x_{j}}=-\frac{\partial \pi}{\partial x_{1}}-\lambda \sigma T \frac{\partial H}{\partial x_{1}}+\frac{\partial}{\partial x_{j}}\left(k_{j} \frac{\partial u_{1}}{\partial x_{j}}\right) \\
\frac{\partial u_{2}}{\partial t}+u_{j} \frac{\partial u_{2}}{\partial x_{j}}=-\frac{\partial \pi}{\partial x_{2}}-\lambda \sigma T \frac{\partial H}{\partial x_{2}}+\frac{\partial}{\partial x_{j}}\left(k_{j} \frac{\partial u_{2}}{\partial x_{j}}\right) \\
\frac{1}{H} \frac{\partial \pi}{\partial \sigma}=\lambda T, \\
\frac{\partial H}{\partial t}+\frac{\partial H u_{1}}{\partial x_{1}}+\frac{\partial H u_{2}}{\partial x_{2}}+\frac{\partial H u_{3}}{\partial x_{3}}=0 \\
\frac{\partial T}{\partial t}+u_{j} \frac{\partial T}{\partial x_{j}}=\frac{\partial}{\partial x_{j}}\left(k_{T j} \frac{\partial T_{j}}{\partial x_{j}}\right) \\
\frac{\partial S}{\partial t}+u_{j} \frac{\partial S_{j}}{\partial x_{j}}=\frac{\partial}{\partial x_{j}}\left(k_{S_{j}} \frac{\partial S_{j}}{\partial x_{j}}\right) .
\end{gathered}
$$

Here, the $\sigma$ system of coordinates is used:

$$
\sigma=\frac{x_{3}-\delta\left(x_{1}, x_{2}\right)}{H\left(x_{1}, x_{2}, t\right)}, \quad H\left(x_{1}, x_{2}, t\right)=h\left(x_{1}, x_{2}, t\right)-\delta\left(x_{1}, x_{2}\right) .
$$

We employ the following boundary conditions:

$$
\begin{aligned}
& k_{3} \frac{\partial u_{i}}{\partial x_{3}}=k_{T p}\left|u_{i}\right| u_{i}, \quad \text { npu } \sigma=0, \\
& k_{S} \frac{\partial S}{\partial x_{3}}=f_{u c m}=\left\{\begin{array}{ll}
f, & x_{j} \in I-u c m . \\
0, & x_{j} \notin I
\end{array},\right. \\
& \frac{\partial T}{\partial x_{3}}=f_{S}, \\
& \frac{\partial H}{\partial t}=u_{3}, \quad \text { given } \quad \sigma=1, \\
& \frac{\partial u_{1}}{\partial x_{3}}=\frac{\partial u_{2}}{\partial x_{3}}=\frac{\partial T}{\partial x_{3}}=\frac{\partial S}{\partial x_{3}}=0, \\
& x_{i}= \pm L_{i}, \quad \frac{\partial u_{i}}{\partial x_{i}}=\frac{\partial T}{\partial x_{i}}=\frac{\partial S}{\partial x_{i}}=0 .
\end{aligned}
$$

and the following initial conditions:

$$
\begin{aligned}
& u_{j}=f_{j 0}, \quad \text { given } t=0, \quad j=1,2, \\
& T=f_{t 0}, \quad \text { given } t=0, \\
& S=f_{s 0}, \text { given } t=0 .
\end{aligned}
$$

To examine the locations of an emergencyfallof twostages of the carrier-rocket"Proton-M" of the state branch enterprise "Infrakos-Ecos", qualitative and quantitativechemical analysesof the environment, such as liquid chromatography andionometry, were conducted, in addition to testsof vegetation cover. 


\section{Modeling Results}

This section describes the modeling results obtained for air pollution caused by the release of heptyl during the "Proton" carrier-rocket falls. These results are based on scenariolb), in whichthe rocket fuelspillageoccurs afterthe carrier-rocketsecond-stage fall with alateralflow,and a comparative analysis is conducted for the modeling results and thecontoursof vegetation cover contamination.

These calculations were performed based on a mesoscale meteorological model for an area of rectangular parallelepiped form. In this case,the source of the pollution is the fall point of the carrier-rocket, which broke upon ground impact.The results of thesecalculations are shown inFigures 1 and 2 .

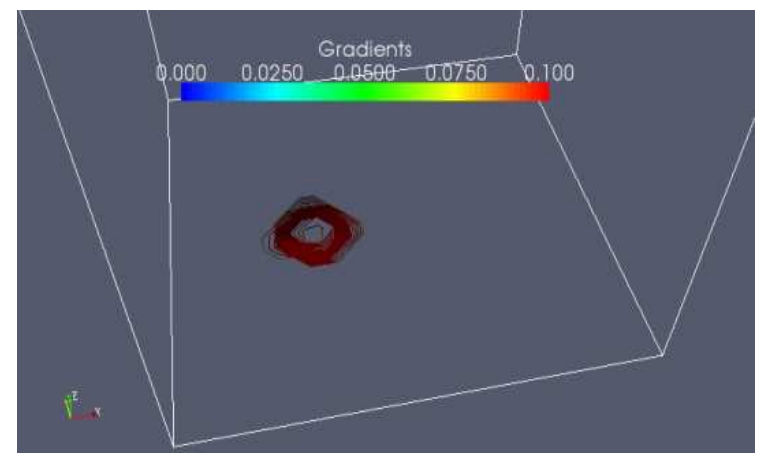

Figure 1.Isolines of rocket fuel component concentration at the initial time of the "Proton" carrier-rocket second-stage emergency fall, under calm conditions.

Figure 1 shows the concentration of the rocket fuel component under calm conditions, while Figure 2 give results for a southwest wind, corresponding to 80 minutes after the carrier-rocket second-stage emergency fall. Figures 3 and 4 show the vertical section of the cloud, which was formed during ground impact, 6 and 9 hours after the carrier-rocket second-stage fall. The maximum concentration of the rocket fuel component is highlighted in red.

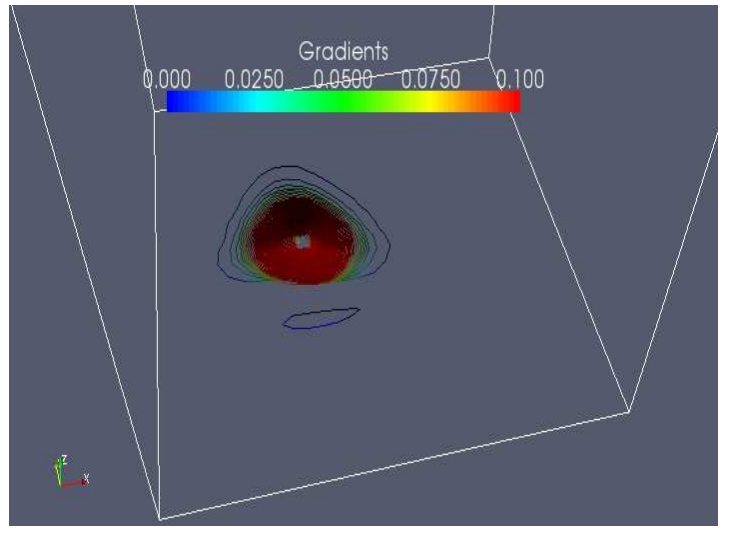

Figure 2.Isolines of rocket fuel component concentration at 80 minutes after the emergency fall of the "Proton" second-stage carrier rocket, under a southwest wind.

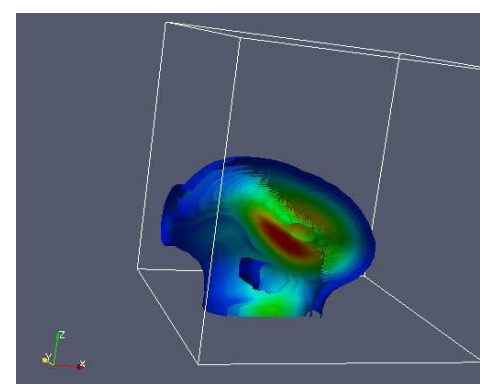

Figure 3.Distribution of rocket fuel concentration, 6 hours after the "Proton" carrier-rocket second-stage emergency fall in a vertical section

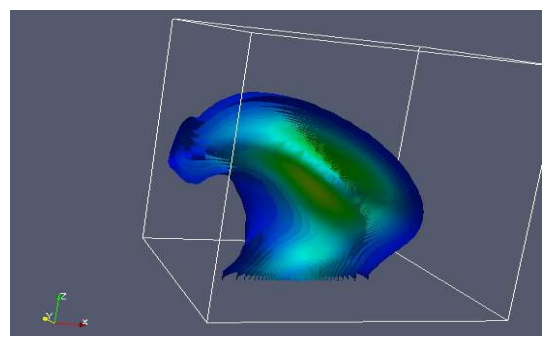

Figure 4. Distribution of rocket fuel concentration 9 hours after the "Proton" carrier-rocket second-stage emergency fall in a vertical section.

Figures 5 - 7 display a comparison between the calculated data and the pollution map for vegetation cover in the region of the carrier-rocket second-stage emergency fall. The full dynamics of the perturbed air masses, up to the attenuation stage, are displayed within the estimated area. A notably strong decrease in the density of the aerosol concentration with time and with increasing distance from the source, even on the leeward side, was observed.

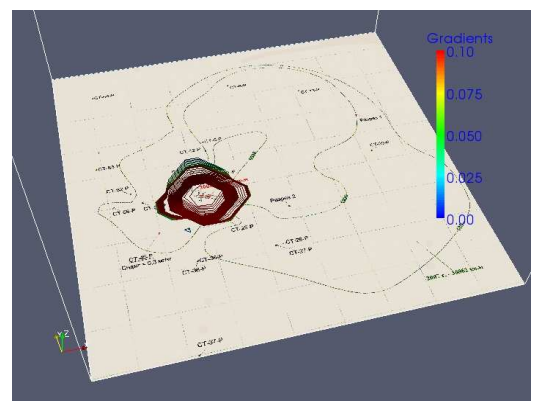

Figure 5.Isolines of rocket fuel component concentration after the "Proton" carrier-rocket second-stage emergency fall, $t=0$, compared to the contamination map for the region of the fall

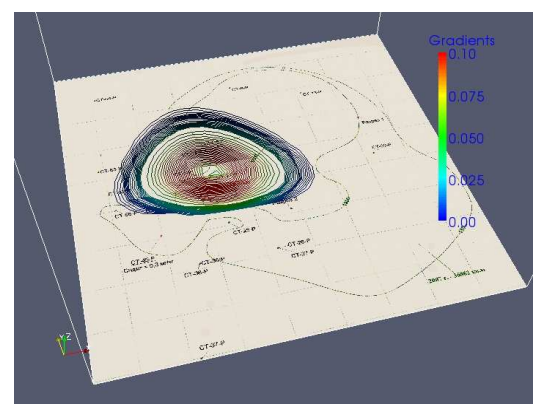

Figure 6.Isolines of rocket fuel component concentration after the "Proton" carrier-rocket second-stage emergency fall, $t=2$ hours, compared to the contamination map for the region of the fall 


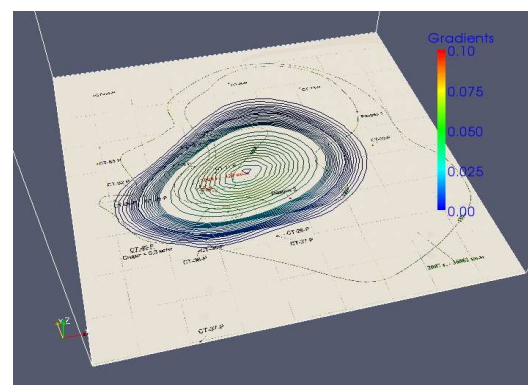

Figure 7.Isolines of rocket fuel component concentration after the "Proton" carrier-rocket second-stage emergency fall, $t=6$ hours, compared to the contamination map for the region of the fall.

The contamination levels due to rocket fuel components in the areas in which the second-stage fall occurs are small because as the second stage enters the atmosphere,strongaerodynamicheating causes thesecond stage to disintegrate andthe remaining fuel is burnt, partiallydissipating in theupper atmosphere and graduallydecomposing due to theultraviolet solarradiation occurring at altitudes ofmore than $50 \mathrm{~km}$.

\section{Conclusions}

The modeling results allow us to conclude that for the rocket-carrier second-stage "Proton", with its fall on the surface of the earth and subsequent explosion, a large portion of the fuel does not burn out but disperses in the atmosphere, as the temperature in the explosion is sufficiently high and the volatility of UDMH increases sharply with increasing temperature. The remaining fuel migrates deep into the soil. The data analysis clearly demonstrates that the levels of UDMH decrease markedly with increasing distance from the fuel tank and propulsion level fall points. Pollution of the surface layer at the location of the carrier-rocket stage fall is observed throughout the entire epicenter of the fall. Maximal pollution of the ground surface is observed at the point of landing of the propulsion system and the fuel tank, where the fuel contaminates the soil. The UMDH concentration falls sharplywith increasing distance from the location of the fall. It should be noted that the modeling is based on data for the worst-case scenario in which all of theheptylresidue from the carrier-rocket second stage is shed at one place.

Thus, the estimates demonstrate that the pollution mainly occurs near the location of the carrier-rocket part fall and in places where transfer over a large distance from the point source on the surface is not possible. The good concordance obtained between the calculated and experimental data allows us to use the proposed model for a wide class of ecological problems associated with technological processes and emergency situations.

\section{References}

[1] E. L. Aleksandrov. "O povedeniikapel' raketnogotopliva v atmosphere"(On the behavior of rocket fuel droplets in the atmosphere), Meteorologijaigidrologija, 1993, № 4, p 36-45.

[2] F. T. M. Newstadt, X. Van Dop “Atmosfernajaturbulentnost' imodelirovanieraspredelenijaprimesej" (Atmospheric turbulence and modeling of the distribution of the contaminants), Leningrad: Gidrometeoizdat, 1985, p 351.

[3] E. G. Klimova, U. N. Morokov and others "Matematicheskajaocenkazonzagrjaznenijapoverhnostizeml iraketnymtoplivompripadeniiotdeljajushhihsjachastejraket-n ositelej" (Mathematical evaluation of the surface contamination by the rocket fuel by the fall of the carrier rocket separating parts), Optikaatmosferyiokeana, 2005, vol. 18, № 5, 6, p 525-529.

[4] U. S. Abdibekov, B. T. Zhumagulov, A. K. Khikmetov "Modelirovanierasprostranenijaprimesi V svobodnoj atmosphere"(Modeling of distribution of contaminants in the free atmosphere), Vychislitel'nyetehnologii, 2003, vol. 8, p 25-36.

[5] U. N.Morokov, E. G. Klimova and others "Modelirovaniezagrjaznenijapoverhnostizemliraketnymtopli vom" (Modeling of the surface contamination by the rocket fuel), Optikaatmosferyiokeana, 2004, vol. 17, № 9, p 769-773.

[6] G. I. Marchuk "Matematicheskoemodelirovanie v problemeokruzhajushhejsredy" (Mathematical modeling in the environmental problem), Moscow: Nauka, Main publishing house of the physic-mathematical literature, 1982, p 320 .

[7] V. F.Raputa, A. P. Sadovskiy, S. E. Olkin, S. V. Zukov, I. K. Reznikova, A.

Smirnova "Ocenkaharakteristikvypadenijraketnogotoplivapo ego soderzhaniju v ozernojvode" (Evaluation of the rocket fuel fallout characteristics as of its content in lake waters), Optikaatmosferyiokeana, 2001, vol. 14, № 1, p 80-83.

[8] A. P. Sadovskiy, V. F. Raputa, S. E. Olkin, S. V. Zukov, I. K. Reznikova "K voprosuobajerozolirovaniigeptila v rajonahpadenijaotdeljaemyhchastejraket-nositelej" (On the issue of the heptylaerosolization in the areas of impact caused by the fall of the separating rocket carrier parts), Optikaatmosferyiokeana, 2000, vol. 13, № 6-7, p 672-677.

[9] N.

N. Yanenko "Metoddrobnyhshagovreshenijamnogomernyhzadachmatem aticheskojfiziki" (Method of fractional steps in solving the multidimentional problems of the mathematical physics), USSR Academy of Sciences - Novosibirsk: Nauka, 1967, p 197.

[10] P. N. Below, Numerical methods of weather forecast. - L.: Gidrometeoizdat, 1975, p 392. 